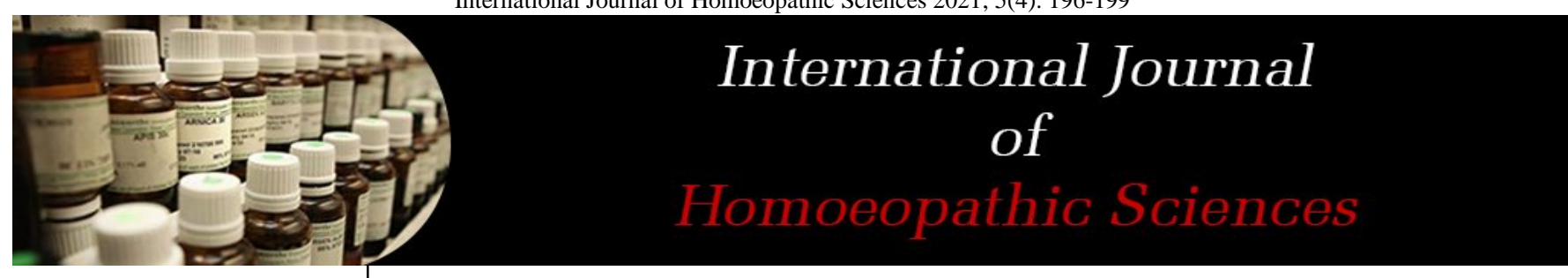

E-ISSN: 2616-4493

P-ISSN: 2616-4485

www.homoeopathicjournal.com

IJHS 2021; 5(4): 196-199

Received: 25-08-2021

Accepted: 26-09-202

Dr. Ashok Yadav

Head of Department,

Department of Practice of

Medicine, Dr. MPK

Homoeopathic Medical

College, Hospital and Research

Centre, Rajasthan, India

Dr. Bhavneet Kaur

MD Scholar, Department of

Practice of Medicine

Dr. MPK Homoeopathic

Medical College, Hospital and

Research Centre, Rajasthan,

India

Dr. Kanika Agarwal

MD Scholar, Department of

Practice of Medicine, Dr. MPK

Homoeopathic Medical

College, Hospital and Research

Centre, Rajasthan, India

Dr. Pawan Choudhary

MD Scholar, Department of

Practice of Medicine, Dr. MPK

Homoeopathic Medical

College, Hospital and Research

Centre, Rajasthan, India
Corresponding Author Dr. Kanika Agarwal MD Scholar, Department of Practice of Medicine, Dr. MPK Homoeopathic Medical College, Hospital and Research Centre, Rajasthan, India

\title{
Juvenile idiopathic arthritis and its homoeopathic approach
}

\section{Dr. Ashok Yadav, Dr. Bhavneet Kaur, Dr. Kanika Agarwal and Dr. Pawan Choudhary}

DOI: https://doi.org/10.33545/26164485.2021.v5.i4c.474

\begin{abstract}
Juvenile idiopathic arthritis (JIA), is the most common rheumatic disease that affects children and is a significant cause of both short and long term disabilities. Specifically, JIA is defined as arthritis of unknown etiology and its diagnosis requires clinical exclusion of other known conditions. Excessive delay in instituting advance treatment for JIA results in irretrievable damage to joints and other organs and impair skeletal maturation. There is no cure in modern system of medicine but in homoeopathy, we can manage this condition with our medicines. This article is about still's disease and its homoeopathic management.
\end{abstract}

Keywords: Still’s disease, juvenile idiopathic arthritis, rheumatic disease, homoeopathy

\section{Introduction}

Juvenile idiopathic arthritis (JIA), formerly known as Still's disease is most common type of arthritis in children. Fever, rash, swelling and pain in joints in children are the key features of this systemic disorder. It is more common in girls under 16 years of age. Hepatosplenomegaly, serositis in association with raised ESR and CRP are the common findings. Autoantibody tests are negative. ${ }^{[1]}$

\section{Epidemiology}

The epidemiology of JIA remains unclear due to non-uniform classification methods and diversity of disease frequencies in different region. Data from literature suggest a disease incidence of 1-22 in 100,000 and a disease prevalence of 7-150 in 100,000 ${ }^{[2-4]}$. A study from Turkey reported a prevalence of chronic arthritis in childhood of 64 in 100,000 [5]. A study from Australia showed prevalence as high as 400 in 100, $000{ }^{[6]}$. Ethnic differences in prevalence have also been noted. The prevalence of JRA is less in blacks than in those of Indian ancestry among South African children ${ }^{[7]}$ and is higher in the native population than among Caucasians among Canadian children ${ }^{[8]}$.

\section{Etiology}

The exact cause of juvenile idiopathic arthritis is still unknown. However it has been thought to arise from various environment and genetic factors. Most responsible factors are infections, together with stress and trauma ${ }^{[9]}$.

Genetic factors involved: HLA B27 and other HLA tissue types are most commonly involved ${ }^{[10-14]}$.

Infections: enteric infections, parvovirus B19, rubella, mumps, hepatitis B, Epstein-Barr virus, mycoplasma and chlamydia infections ${ }^{[15-16]}$.

\section{Pathogenesis}

Potential trigger-induced T-lymphocytes and secreted cytokines lead to joint destruction. Pro-inflammatory cytokines [interleukin (IL) 1, IL-6, tumor necrosis factor (TNF)- $\alpha$ ] are produced by Macrophages which are induced by secreted mediators. Consequently, the acute phase markers [C-reactive protein (CRP), erythrocyte sedimentation rate (ESR)] increase and the acute inflammation of joints occurs along with increase in synovial fluid. Synovial inflammation or synovitis is characterized by villous hypertrophy and hyperaemia of the subsynovial tissue. 
Secondary to chronic inflammation, Synovial hypertrophy and synovitis occurs and are known as "Panni”.

The T-lymphocyte percentage in synovial fluids varies among different JIA subtypes ${ }^{[5-6]}$.

Subtypes and clinical features of JIA ${ }^{[17]}$

Table 1: Subtypes and Clinical features of JIA

\begin{tabular}{|c|c|c|c|}
\hline Subtype & Frequency & Clinical features & Immunology \\
\hline Systemic JIA & $5 \%$ & Fever, rash, arthralgia, hepatosplenomegaly & Auto-antibody negative \\
\hline Oligoarthritis ( $\leq 4$ joints) & $60 \%$ & Large joint arthritis, uveitis & ANA* positive \\
\hline Polyarthritis ( $\geq 5$ joints) & $20 \%$ & Polyarthritis, maybe extended form of oligoarthritis & ANA positive \\
\hline Enthesis-related & $5 \%$ & Sacroilitis, enthesopathy & RFA* Positive, ACPA* Positive \\
\hline Rheumatoid factor positive & $5 \%$ & Polyarthritis, similar to RA* & Autoantibody negative \\
\hline Epsoriatic arthritis & $5 \%$ & Same as adult disease & \\
\hline
\end{tabular}

*ANA- Antinuclear antibody

*HLA- Human Leukocyte antigen

*ACPA- Anti citrullinated peptide antibody

*RA- Rheumatoid factor

Uveitis maybe clinically silent and persist into adulthood, necessitating routine screening for eye involvement.

\section{Investigations: ${ }^{[18]}$}

\section{A. Hematological investigations}

1. CBC: May show anemia of chronic disease, low serum iron, low total iron-binding capacity, adequate hemosiderin store, leukocytosis, increase platelet count

2. ESR: ESR is elevated and is used to determine the degree of inflammation.

3. C reactive protein $(\mathbf{C R P})$ : Levels are elevated and indicates the degree of general inflammation.

4. Antinuclear antibody (ANA): Positive. It is a marker for chances of inflammation of eyes.

5. Rheumatoid factor (RA): Positive. Indicates high risk of damage from arthritis.

6. Cyclic citrullinated peptide (CCP): Positive. Indicates high risk of damage.

B. Imaging scans

1. Radiographs: Quick, easy and affordable method for evaluation of joints. Common x-ray findings are soft tissue swelling, loss of joint space, irregularity of joint surfaces, periosteal new bone formation and growth disturbance.

2. USG: For identifying intra-articular fluids in joints such as hip joint, shoulder joint.

3. MRI: To detect inflammatory changes in joints and cartilage damage, precisely evaluate the later manifestations of JIA, including erosions, loss of joint space, cartilage damage, and ligamentous involvement.

\section{Other Investigations}

1. Arthrocentesis: Often known as joint aspiration. Removing and testing the synovial fluid of affected joints can be used to rule out infection and aid in identifying the cause of the arthritis.

2. Synovial Biopsy: Removal of a small portion of the synovial tissue from the affected joint aid in determining the cause of the inflammation and synovial damage.

\section{Management}

General management
1. Rest during acute stage.

2. Reassurance and emotional support to patient and family members.

Homoeopathic management: ${ }^{[19-20]}$

1. Thuja occidentalis

Constitution: It is adapted to hydrogenoid constitution.

Eyes: Ciliary neuralgia, inflammation of iris. Eyelids are agglutinated at night.

Locomotor system: Cracking in joints. When walking, the patient feels as if limbs are made of glass/wood or would break easily. Child suffers with pain in heels and tendo Achilles. There is muscular twitching. There is great weakness and trembling. Nails are brittle. Ingrown toe nails. Tips of fingers are red and swollen.

Skin: Child has dirty skin. Brown spots on hands and arms. The skin is very sensitive to touch.

Fever: Chill begins in the thigh. Sweat only on the uncovered parts or all over except the head, only when he sleeps, stops when he wakes up. Sweat is sour, profuse and smells like honey on genitals. There is orgasm of blood in evening, with throbbing pain in blood vessels.

\section{Medorrhinum}

Constitution: Children are pale and rachitic. They are dwarfed and stunted in growth. Mentally dull and weak. Child is irritated at trifles, cross during day, exhilarated at night.

Eyes: Eyeballs ache. Lids are irritated. Patient feels as if sticks in eyes.

Locomotor system: Rheumatism at the top of shoulder and arm. This pain radiates to fingers, >by motion. Pain in legs, from hip to knees, which is present only while walking. Legs feel heavy, like lead. Walking is difficult, due to heaviness feeling in leg, legs give way. Ankles turn easily when walking. Entire loss of nervous force in legs and arms, exhausted by little effort. Lower limbs ache all night which prevents sleep. Intense restless and fidgety feet. During electrical storm, there is terrible burning in legs and arms, wants them uncovered. Deformity of finger joints, large, puffy knuckles. Great tenderness of heels and balls of feet. 
Skin: Fiery red rash about anus in babies. Copper colored spots on skin. Yellow skin with intense itching, which is worse at night and when thinking of it.

Fever: During fever, wants to be fanned. Chills run up and down the back, coldness of legs, arms and forearm. Flashes of heat in face and neck. Night sweats.

\section{Tuberculinum}

Constitution: Child has flat, narrow chest. He is active and precocious mentally but weak physically. Diathesis is tubercular. There is rapid and pronounced emaciation. Patient loses weight while eating well. There is marked irritability especially on awakening.

Locomotor system: There is tension in the nape of neck and down the spine. Chilliness between shoulders or up the back.

Skin: fiery red skin. Intense itching $<$ at night when undressing, from bathing, immense quantities of white bram like scales. There is oozing behind ears, in the hair, in folds of skin with rawness and soreness.

Fever: Post critical temperature of a remittent fever. Profuse sweating and great chilliness.

\section{Calcarea carbonica}

Constitution: Psoric constitutions, pale, weak and timid. Children has tendency to grow fat. Children with red face, flabby muscles. They sweat profusely and catch cold easily.

Eyes: Eyes are sensitive to light. Lachrymation in open air and early in morning. Eyes fatigue easily.

Locomotor system: Curvatures of bone especially spine and long bones. Rheumatoid pains, as after exposure to wet. Rheumatism in lumbar region. Nape of neck stiff and rigid. Pain between shoulder blade, impeding breathing Pains are sharp sticking as if parts were wrenched or sprained. Cold damp feet as if damp stockings were worn. Cold knees with cramps in calves. Feet feel cold and damp at night. Sweat of hands and sour foot sweat. Swelling of joints especially knee joint. Burning of soles of feet, raw soles. Arthritic nodules are seen.

Skin: Skin is unhealthy. Petechial eruptions are seen.

Fever: Chill begins at 2pm, felt internally in stomach region. Frequent and full pulse. Chilliness and heat. Hectic fever. Sweat in head of children, so that pillow becomes wet.

\section{Abrotanum}

Constitution: Child is irritable, anxious and depressed. There is marked emaciation of legs.

Locomotor system: There is excessive pain before swelling commences resulting from suddenly checked diarrhea or other secretions. Rheumatism alternates with haemorrhoids/ dysentery. Pricking and coldness in fingers and feet. Painful contractions of limbs from cramps or following colic. Pricking and coldness in fingers and feet.
Skin: Skin is flabby and hangs loose in folds. Eruptions come out on face which are suppressed. The skin becomes purplish.

Fever: Great weakness and prostration and a kind of hectic fever.

\section{Aconitum napellus}

Constitution: Great fear with anxiety of mind. Nervous excitability of mind.

Eyes: Eyes are red and inflamed. Eyes feel dry and hot as if sand in them. Lids swollen, hard and red. Profuse watering after exposure to dry cold winds.

Locomotor system: Rheumatic inflammation of joints which is worse at night. Red, shining swelling which is very sensitive. Arms feel lame, bruised, heavy, and numb. Hip joint and thigh feel lame especially after lying down. Unsteady-knees Feet are disposed to turn. Sensation as if drops of water tickled down the thigh.

Skin: Skin is red, hot, dry and swollen. Measles like rash are seen.

Fever: Cold stage is most marked. Cold waves pass through him. Evening chilliness soon after going to bed. Feels chilly if uncovered or touched. Restless, mental anguish and thirst present throughout. Drenching sweat on parts laid on which relieves all symptoms.

\section{Apis Mellifica}

Constitution: Suited to children who are generally careful but becomes awkward and let things fall while handling them.

Eyes: Bright red, puffy conjunctiva. Hot lachrymation.

Locomotor system: Shiny, swollen, sensitive, sore knee with stinging pain. Feet are swollen and stiff and feels too large. Rheumatic pains in back and limbs. Tired and bruised feeling. Hands and tip of fingers feel numb.

Skin: Sudden puffing of whole body. Soreness and sensitiveness of skin.

Fever: Chill come in afternoon, with thirst which is worse on motion and heat. There is external heat. Perspiration breaks out and dries up frequently. Sleeps after the fever paroxysm.

\section{Arsenic album}

Constitution: Child is mentally restless but physically too weak to move. Gradual loss of weight from impaired nutrition.

Eyes: Ciliary neuralgia with burning pain. Burning hot and acrid lachrymation.

Locomotor system: There is swelling of feet. Weak extremities. There is trembling, twitching and uneasiness in limbs.

Skin: There are oedematous eruptions with much itching and burning. Skin is dry, rough and scaly. 
Fever: There is high rise of temperature. Periodicity is marked. Fever comes in paroxysm with marked emaciation. There is great restlessness with great heat around $3 \mathrm{a} . \mathrm{m}$.

\section{Belladonna}

Constitution: Children with light hair and blue eyes, fine complexion, delicate skin, sensitive, nervous.

Eyes: Eyes feel swollen with fiery red appearance. Fundus is congested.

Locomotor system: Shooting pain along limbs. Joint swollen, red, shining with red streaks. Gait is tottering. Involuntary limping present.

Skin: Dry, hot, swollen and sensitive skin. Alternate redness and paleness of skin.

Fever: A high feverish state with comparative absence of toxaemia. Pulse is full, bounding and globular like buckshot striking fever. No thirst with fever. Sleepy but cannot sleep. Perspiration is dry, only on head.

\section{Mercurius solubilis}

Constitution: It is best adapted to persons with light hair. Eyes: Iritis with hypopyon. Profuse burning with acrid discharge.

Locomotor system: There is weakness of limbs. Bone pains and limbs worse at night. Lacerating pain in joints. There is trembling in extremities especially hands. Cold, clammy sweat on legs at night.

Skin: Vesicular and pustular eruptions.

Fever: Profuse nightly yellow perspiration without relief. Creeping chilliness worse in evening and night. Alternate flashes of heat in single parts

\section{Discussion and Conclusion}

Juvenile Idiopathic Arthritis is a common type of arthritis affecting children. If not treated appropriately, it may lead to disability and decrease quality of life. Homoeopathy is the system of medicine which is based on law of "similia similibus curenter” have great potential in managing cases of JIA along with general management. Homoeopathic materia medica have numerous remedies which when judiciously implemented can manage such cases successfully.

\section{References}

1. William C, Shiel JR. Still's disease (Systemic-Onset Juvenile Idiopathic Arthritis). Medicinenet.com [Internet] September 2021[cited 25.9.2021]; Available from:

https://www.medicinenet.com/stills_disease/article.htm

2. Gowdie PJ, Tse SM. Juvenile idiopathic arthritis. Pediatr Clin North Am 2012;59:301-27.

3. Weiss JE, Ilowite NT. Juvenile idiopathic arthritis. Pediatr Clin North Am 2005;52:413-42.

4. Prakken B, Albani S, Martini A. Juvenile idiopathic arthritis. Lancet 2011;377:2138-49.
5. Ozen S, Karaaslan Y, Ozdemir O, Saatci U, Bakkaloglu A, Koroglu E et al. Prevalence of juvenile chronic arthritis and familial Mediterranean fever in Turkey: A field study. J Rheumatol 1998;25:2445-9.

6. Manners PJ, Diepeveen DA. Prevalence of juvenile chronic arthritis in a population of 12-year-old children in urban Australia. Pediatrics 1996;98:84-90.

7. Haffejee IE, Raga J, Coovadia HM. Juvenile chronic arthritis in black and Indian South African children. S Afr Med J 1984;65:510.

8. Hill R. Juvenile arthritis in various racial groups in British Columbia. Arthritis Rheum 1977;20:S162. (Abstract).

9. Weiss JE, Ilowite NT. Juvenile idiopathic arthritis. Pediatr Clin North Am 2005;52:413-42.

10. Ross E, Petty RML, Lucy R. Wedderburn. Juvenile Idiopathic Arthritis. In: Petty RE, Laxer RM, Lindsley CB, Wedderburn LR, eds. Textbook of Pediatric Rheumatology: Elsevier Saunders Company 2016, 188284.

11. Adrovic A, Barut K, Sahin S, Kasapcopur O. Juvenile Spondyloarthropathies. Curr Rheumatol Rep 2016;18:55.

12. Aggarwal A, Misra DP. Enthesitis-related arthritis. Clin Rheumatol 2015;34:1839-46.

13. Ferucci ED, Majka DS, Parrish LA, Moroldo MB, Ryan M, Passo M et al. Antibodies against cyclic citrullinated peptide are associated with HLADR4 in simplex and multiplex polyarticular-onset juvenile rheumatoid arthritis. Arthritis Rheum 2005;52:239-46.

14. Hinks A, Bowes J, Cobb J, Ainsworth HC, Marion MC, Comeau ME et al. Fine-mapping the MHC locus in juvenile idiopathic arthritis (JIA) reveals genetic heterogeneity corresponding to distinct adult inflammatory arthritic diseases. Ann Rheum Dis 2016 [Epub ahead of print]

15. Aslan M, Kasapcopur O, Yasar H, Polat E, Saribas S, Cakan $\mathrm{H}$ et al. Do infections trigger juvenile idiopathic arthritis? Rheumatol Int 2011;31:215-20.

16. Gonzalez B, Larrañaga C, León O, Díaz P, Miranda M, Barría M et al. Parvovirus B19 may have a role in the pathogenesis of juvenile idiopathic arthritis. J Rheumatol 2007;34:1336-40.

17. Walkar Brain R, Colledge Nicki R, Ralston Stuart H, Penman lan D. Davidson's Principles and Practice of Medicine. $22^{\text {nd }}$ edition. Edinburg, Churchill livingstone/ Elsevier, 2014.

18. Kim KH, Kim DS. Juvenile Idiopathic Arthritis; Diagnosis and differential diagnosis. Korean J Pediatr 2010;53(11):931-935.

19. Allen HC. Keynotes and Characteristics with comparisons of the some of leading remedies of the Materia Medica. Kolkata: Medical Book Publication, 2002.

20. Boericke W. Pocket manual of homoeopathic Materia Medica: comprising the characteristic and guiding symptoms of all remedies (Clinical and Pathogenetic). New Delhi: Indian Books \& periodicals Publishers, 2012. 